\title{
Commercial confidentiality: a cloak for policy failure
}

The Department of Health in England is increasingly putting itself beyond the reach of parliament and public scrutiny when it makes fundamental changes to the NHS. Evaluations of six commuter walk-in centre pilot schemes published in this issue of the $B J G P$ were limited because the researchers, despite being funded by the Department of Health, were denied access to both the contract and patient data. The Department of Health deemed the data commercial in confidence in one study and in the other study - despite having agreed to provide the data - withdrew permission on the same grounds. ${ }^{1,2}$ Since 2002 the government has argued that complete accountability of publicly-funded programmes will stifle innovation; so which stakeholder interests are being served by this latest exercise in policy secrecy? ${ }^{3}$

The background to the research is the UK general medical services (GMS) contract of 2003, which heralded the major market-oriented reforms allowing primary care and GP services to be broken up and put out to tender to large multinational corporations and new alternative providers of care [Health and Social Care (Community Health and Standards) Act 2003]. Among the new alternative providers of care are six commuter walk-in centres, which are paid for by NHS funds but provided by four private sector companies: Atos Healthcare, Netcare UK, Walk in Health, and Care UK. A seventh centre will be soon be opened in London. The centres, located near rail stations, were intended to provide primary care services to both commuters and the local population, improve access, and widen patient choice. The contracts for the six centres are estimated to cost the NHS $£ 50$ million over 5 years. ${ }^{1}$

Value for money claims about the efficiency, performance, and benefits of the market can only be tested by having full access to the contract details, the costs of services, and the numbers of patients treated. Denied access to these data, the researchers had to rely on patient surveys, staff interviews, and press releases, providing only a partial picture..$^{1,2}$

Their findings show that the centres were working at around half the rate intended; that is, an average of 87 patients attended each day compared with the 150-180 patients expected. The contract price was $£ 50$ million over 5 years; if the underperformance continues at the same rate across the life of the contract, up to $£ 25$ million - half the contract - could be overpaid by the NHS to the private sector during the 5-year period; but without the patient data and the contract details we shall never know for sure.

As one would expect, patients attending the commuter walk-in centres are younger and fitter: $84 \%$ of those surveyed were $<45$ years, while only $1 \%$ were $\geq 65$ years. In contrast, the highest rates for GP consultations nationwide are among those aged $\geq 65$ years, reflecting higher sickness rates. ${ }^{4}$ The skewed demographics raise questions as to the basis of the reimbursement of the Department of Health contracts. What the researchers do show is that, on the basis of actual attendance, walk-in centres are being paid between two and four times the estimated cost per attendance at an NHS GP surgery, and this despite their younger, healthier patient population. ${ }^{1,2}$

Information is not just the lifeblood of democracy, it is the cornerstone of both public health care and the efficient functioning of markets. In the public health paradigm - within which a universal service such as the NHS operates - data and information are required to ensure that the goals of universal access, equity, and comprehensive care are being monitored and met and services adapted accordingly. Data are required to monitor and evaluate the population's access to health care; its use of services; met and unmet need; and any inequities in provision by place, over time or by social class and other factors.

Markets are inherently characterised by information asymmetry, a deficiency which must be overcome by state regulation. In a market the role of regulation is to provide information that allows the consumer to make informed decisions on the basis of quality and cost. In this case, the primary care trust (PCT) is a proxy for the consumer, as the transaction costs of making an informed judgment are too great for the patient. Investors and shareholders also need information to ensure the profitability of services, identify how costs are structured, and how efficiencies can be made. However, PCTs do not manage these contracts; they are nationally procured by the Department of Health, and at least one PCT has consequently found it difficult to assess the performance of these centres due to the poor quality of data they received. ${ }^{5}$ That the taxpayer and citizen might be interested in the efficiency of NHS-funded, private for-profit walk-in centres appears to have eluded the Department of Health, so intent is it upon the project of breaking up NHS services and bringing in for-profit corporations using commercial contracts to run services.

And here's the rub: as with the banks and the East Coast train line, when the market in health care fails the government takes the services back as provider of last resort. At the time of writing, the NHS Choices website stated that the Department of Health is:

\section{'... taking [the seven centres] over from the independent sector ...'. ${ }^{6}$}

However, we have as yet been unable to obtain further confirmation regarding this development.

The question is: what have been, and continue to be, the opportunity costs for the NHS, patients, staff, and citizens of paying too much for these private-sector white elephants? How many chiropody, physiotherapy, and speech therapy services have been cut to pay for care? How much care have older people, the frail, or chronically sick had to forego to satisfy the whims and needs of the walking 
well? Instant gratification for the walking well comes at a price - a price that is increasingly difficult to determine in the context of commercial confidentiality clauses and exemptions in the Freedom of Information (Fol) Act. But there are wider consequences for the continuity of care and monitoring of outcomes.

As health care is being re-modelled by the needs of the market, the universal norms of information are being eroded, namely the data required to monitor cost, access, and universal coverage. This development has grave implications for the ways in which research is undertaken in the future.

Commuter walk-in centres are only a small part of the larger picture. As the government pursues its £5 billion independent sector treatment centre (ISTC) programme, its $£ 15.5$ billion private finance initiative (PFI) hospital programme, and its £12.4 billion IT programme, the exemptions in the Fol Act are being used as an obstacle to both patient and public interest. Extrapolating findings from one case study of an ISTC in Scotland, where contract and patient data were made available under the Fol Act, the NHS may have overpaid the private sector by up to $£ 927$ million for services provided in ISTCs. $^{7}$
As these studies reveal, NHS patients attending commuter walk-in centres are being rendered invisible by the market, and so too are the true costs of NHS care and the losses to patients. Commercial confidentiality and qualified accountability function as a cloak for Department of Health policy failings. It is no surprise the approach finds favour in Whitehall.

\section{Allyson M Pollock,}

Professor of International Public Health Policy, Centre for International Public Health Policy, School of Health in Social Science, University of Edinburgh, Edinburgh.

\section{Liz Richardson,}

Research Assistant, Centre for International Public Health Policy, School of Health in Social Science, University of Edinburgh, Edinburgh.

\section{Provenance}

Commissioned; not peer reviewed.

\section{REFERENCES}

1. O'Cathain A, Coster J, Salisbury C, et al. Do walk-in centres for commuters work? A mixed methods evaluation. Br J Gen Pract 2009; DOI: 10.3399/bjgp09X473150.

2. Coster J, O'Cathain A, Nicholl J, Salisbury C. User satisfaction with commuter walk-in centres. Br J Gen Pract 2009; DOI: 10.3399/bjgp09X473169.

3. HM Government. Audit and accountability in central government. The Government's response to Lord Sharman's report 'Holding to Account'. CM5456. Norwich: HMSO, 2002.
4. Hippisley-Cox J, Vinogradova Y. Trends in consultation rates in general practice 1995 to 2008: analysis of the QResearch ${ }^{\circledR}$ database. Final report to the NHS Information Centre and the Department of Health. London: NHS Health and Social Care Information Centre, 2009.

5. Leeds Primary Care Trust. Board meeting notes: Thursday, 18 September 2008.

http://www.leedspct.nhs.uk/attachment/e7b2c3bb40c 3f78be49766a9c0e35f6f/7320419af149e755558d17107 $1 \mathrm{~b} 8 \mathrm{f} 47 \mathrm{~b} /$ September+2008+Board + papers.pdf (accessed 5 Nov 2009).

6. NHS Choices website. NHS walk-in centres FAQs. http://www.nhs.uk/NHSEngland/AboutNHSservices/ Emergencyandurgentcareservices/pages/WalkincentresFAQ.aspx\#q04 (accessed 5 Nov 2009).

7. Pollock A, Kirkwood G. Independent sector treatment centres: the first independent evaluation, a Scottish case study. J R Soc Med 2009; 102: 278-286.

DOI: 10.3399/bjgp09X473114

\section{ADDRESS FOR CORRESPONDENCE}

\section{Allyson Pollock}

Centre for International Public Health

Policy, School of Health in Social

Science, University of Edinburgh, Teviot

Place, Edinburgh, EH8 9AG.

E-mail: allyson.pollock@ed.ac.uk 